\title{
A Case of Intertriginous and Flexural Exanthema caused by Amoxicillin
}

*Bárbara Cancela-Díez, ${ }^{1}$ David López-Delgado, ${ }^{2}$ José Aneiros-Fernandez, ${ }^{3}$ Ricardo Ruiz-Villaverde ${ }^{2}$

$$
\text { حالة طَفِحِيَّة مَذَحِيّة ثنيْيَّيّة سببها دواء اموكسيسيللين }
$$

بـاربرا كانسيلا-دياز، ديفيد اوبز-ديلقادو، هوزي انيروس-فيرناندز، ريكاردو رويز-فيلافيردي

ABSTRACT: We report a 50-year-old male patient who presented to the Dermatological Outpatient Clinic at the Hospital Universitario San Cecilio, Granada, Spain, in 2017 with symmetrical inguinal eruption and eruption on the dorsum of both feet four hours after the intake of amoxicillin. Physical examination showed confluent non-palpable purpuric macules covering the dorsum of both feet and medial malleolus, giving rise to dusky erythema in some areas. Only oral antihistamines were prescribed and cutaneous exanthema resolved within three weeks. Symmetric drug-related intertriginous and flexural exanthema (SDRIFE) is a sub-type of systemic allergic contact dermatitis, where previous sensitisation can only be demonstrated in up to $50 \%$ of patients by skin patch testing. Therefore, a provocation test was performed with amoxicillin without prior skin patch testing. As drug provocation produced the same reaction, the patient was diagnosed with SDRIFE. A parvovirus B19 infection was ruled out by negative serology. SDRIFE is challenging to distinguish from other skin rashes with similar features and distribution; it is important to be aware of these characteristics and their possible causes.

Keywords: Exanthema; Amoxicillin; Drug Allergy; Drug Eruption; Groin; Feet; Case Report; Spain.

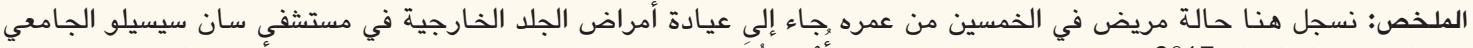

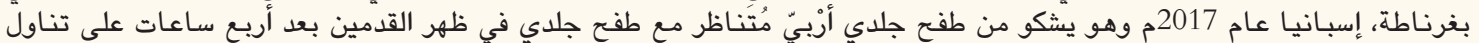

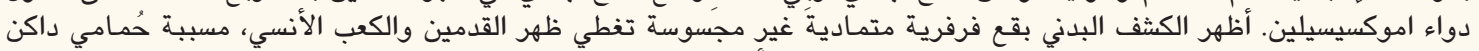

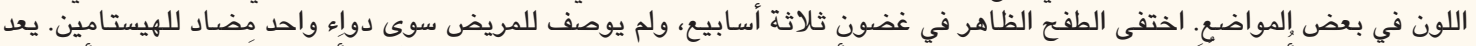

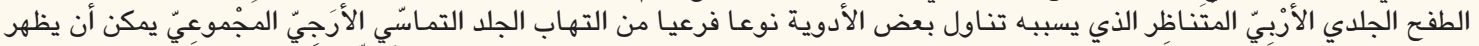

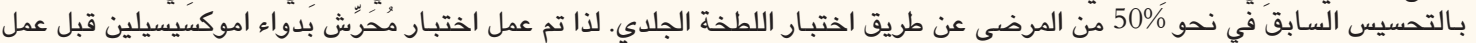

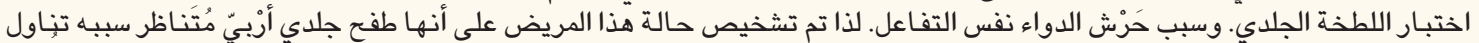

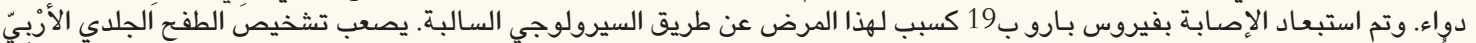

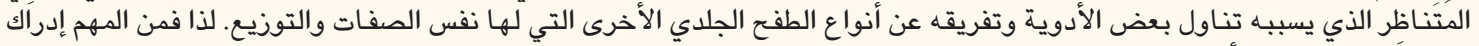

$$
\begin{aligned}
& \text { خواصَ ذلك الَّرض يسبَ وأسبابه الممكنة. } \\
& \text { الكلمات المفتاحية: طَفَحِّة؛ اموكسيسيلين؛ أرجية الدواء؛ طفح جلدي؛ أقدام؛ الأربية؛ تقرير حالة؛ إسبانيا. }
\end{aligned}
$$

$\mathrm{B}$ ABOON SYNDROME (BS) IS A SYSTEMIC contact dermatitis which occurs after systemic exposure to an allergen in previously sensitised individuals. It was first described by Andersen et al. and subsequently, Häusermann et al. proposed the term "symmetric drug related intertriginous and flexural exanthema" (SDRIFE) as BS may be considered a derogatory term. ${ }^{1,2}$

\section{Case report}

A 50-year-old male patient presented to the Dermatological Outpatient Clinic at the Hospital Universitario San Cecilio, Granada, Spain, in 2017 complaining of symmetrical inguinal eruption that was subsequently followed by a similar rash on the dorsum of both feet. Symptoms appeared four hours after the intake of amoxicillin for a respiratory infection (500 mg every eight hours for three days). The patient had a history of allergies to penicillin and codeine, yet no provocation test had previously been performed. In addition, the patient had Swyer-JamesMacLeod syndrome, hepatomegaly and hypertension. He did not smoke or drink alcoholic beverages. There was no history of other drug use except enalapril for hypertension. Physical examination showed confluent non-palpable purpuric macules covering the dorsum of both the feet and medial malleolus, giving rise to dusky erythema in some areas [Figure 1]. Ill-defined erythema with no obvious purpura was found in the groin [Figure 2]. Blood cell count, coagulation profile, renal and liver function tests were all within normal range. The patient did not show systemic signs or symptoms. Parvovirus B19 had been negative in 


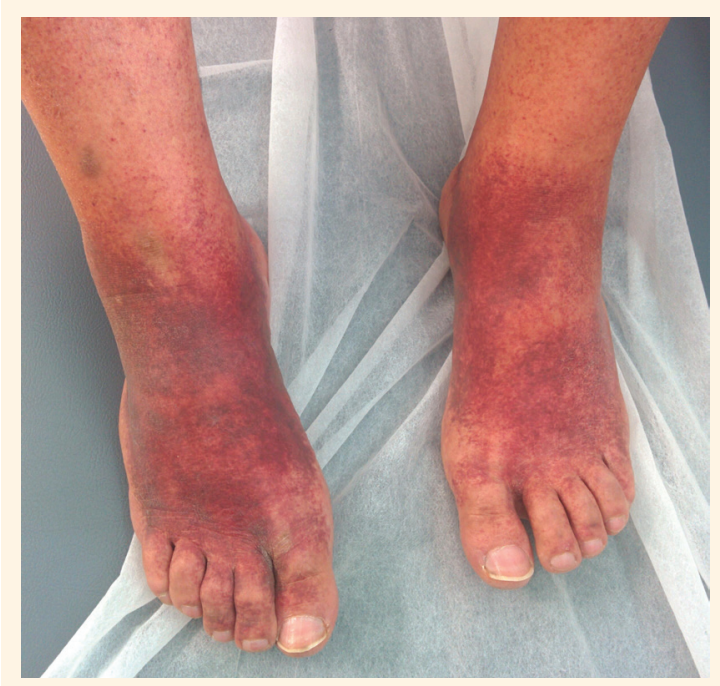

Figure 1: Photograph of the feet of a 50-year-old male patient showing non-palpable purpuric erythema on the dorsum of both feet.

serology. Subsequently, the patient was admitted to hospital for clinical observation. Amoxicillin was stopped and bilastine ( $20 \mathrm{mg} /$ day) was prescribed for 20 days. The cutaneous exanthema resolved within three weeks.

After resolution of the rash, with the patient's consent, a provocation test was performed with one dose of amoxicillin $500 \mathrm{mg}$ without prior skin patch testing. The result of the provocation test was positive as the patient developed the same eruptions at the same locations within 48 hours; therefore, the patient was diagnosed with SDRIFE by amoxicillin.

\section{Discussion}

SDRIFE is defined by the following criteria: (1) systemic exposure to a drug for the first time or repeatedly; (2) symmetrically distributed well-demarcated erythema in the gluteal/perianal area and/or V-shaped erythema in the inguinal/perigenital area; (3) at least one other intertriginous or bending area being affected; and (4) absence of systemic signs and symptoms. ${ }^{2}$ Differential diagnosis includes inflammatory dermatological conditions such as allergic contact dermatitis, irritant contact dermatitis and inverse psoriasis, and infectious entities such as mainly intertrigo and tinea cruris. ${ }^{3}$ It is also important to exclude a parvovirus B19 infection, as this may present clinically with a wide variety of dermatological features, including the same flexural erythema of SDRIFE. In the current patient, papular-purpuric gloves and socks syndrome was also considered, but his hands were not affected. ${ }^{4}$

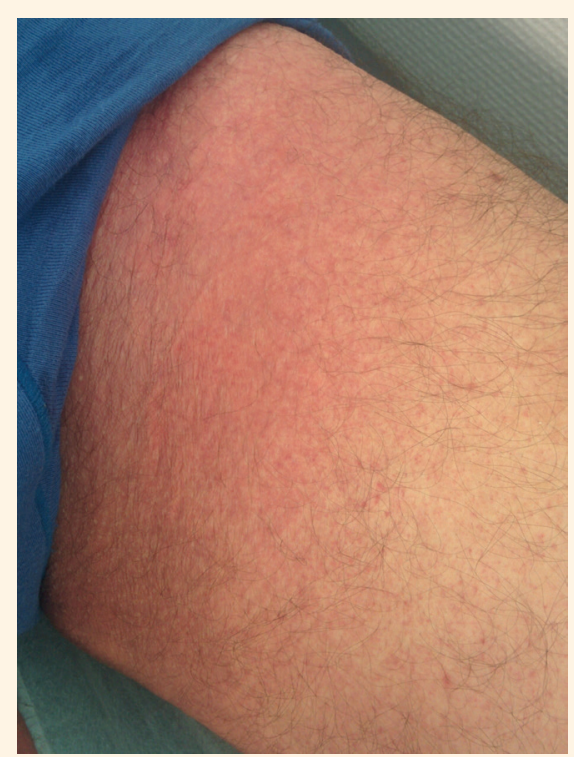

Figure 2: Photograph of the groin of a 50-year-old male patient showing ill-defined erythema in the inguinal area.

Several cases of SDRIFE after exposure to amoxicillin have been previously reported., ${ }^{3,5-7}$ However, SDRIFE has also been associated with other drugs such as rivastigmine, risperidone, valaciclovir and chemotherapeutics agents among others. ${ }^{3,8}$ More recently, SDRIFE has been associated with pristinamycin, secnidazol, nefopam and mefenamic acid.,10 Skin lesions are frequently distributed on the gluteal and intertriginous areas. The current case showed lesions on the upper thighs near the groin, but not in other traditional areas (such as the buttocks). In addition, lesions appeared on the dorsal feet, which has not been reported previously. The skin lesions mostly reported for SDRIFE are maculopapular erythema or plaques. However, one case with petechial eruptions and oral mucosal involvement has been previously reported. ${ }^{11}$ Similarly, the current patient presented with non-palpable purpura in the dorsum of the feet and ankles in addition to ill-defined erythema on the groin; these are very unusual findings in SDRIFE. The onset of the eruption can range from hours to two days after the systemic administration of the medication. ${ }^{3}$ The current patient's symptoms developed within four hours.

A biopsy was not performed as the histopathology in SDRIFE shows non-specific features. Typically, a superficial perivascular infiltrate of mononuclear cells is observed and may include some neutrophils and eosinophils. ${ }^{9}$ It is important to be aware, that previous sensitisation can only be demonstrated in up to $50 \%$ of patients by skin patch testing. ${ }^{12}$ 


\section{Conclusion}

SDRIFE is a cutaneous adverse drug reaction, with distinct characteristic distribution and presentation of the rash. For clinicians, it is important to recognize and distinguish a hypersensitivity reaction from other dermatoses in order to prevent future accidental reexposures. As shown in the current case, the atypical distribution of the lesions should be taken into account in order to provide a correct differential diagnosis.

\section{References}

1. Andersen KE, Hjorth N, Menné T. The baboon syndrome Systemically-induced allergic contact dermatitis. Contact Dermatitis 1984; 10: 97-100. https://doi.org/10.1111/j.1600-05 36.1984.tb00343.x

2. Häusermann P, Harr T, Bircher AJ. Baboon syndrome resulting from systemic drugs: Is there strife between SDRIFE and allergic contact dermatitis syndrome? Contact Dermatitis 2004; 51:297-310. https://doi.org/10.1111/j.0105-1873.2004.00445.x.

3. Winnicki M, Shear NH. A systematic approach to systemic contact dermatitis and symmetric drug-related intertriginous and flexural exanthema (SDRIFE): A closer look at these conditions and an approach to intertriginous eruptions. Am J Clin Dermatol 2011; 12:171-80. https://doi.org/10.2165/11539080000000000-00000.

4. Vargas-Díez E, Buezo GF, Aragües M, Daudén E, De Ory F. Papular-purpuric gloves-and-socks syndrome. Int J Dermatol 1996; 35:626-32. https://doi.org/10.1111/j.1365-4362.1996.tb03686.x.
5. Handisurya A, Stingl G, Wöhrl S. SDRIFE (baboon syndome) induced by penicillin. Clin Exp Dermatol 2009; 34:355-7. https://doi.org/10.1111/j.1365-2230.2008.02911.x.

6. Dogru M, Ozmen S, Ginis T, Duman H, Bostanci I. Symmetrical drug-related intertriginous and flexural exanthema (baboon syndrome) induced by amoxicillin-clavulanate. Pediatr Dermatol 2012; 29:770-1. https://doi.org/10.1111/j.1525-1470.20 $11.01577 \mathrm{x}$.

7. Kick G, Przybilla B. Delayed prick test reaction identifies amoxicillin as elicitor of baboon syndrome. Contact Dermatitis 2000; 43:366-7.

8. Powers R, Gordon R, Roberts K, Kovach R. Symmetrical drugrelated intertriginous and flexural exanthema secondary to topical 5-fluorouracil. Cutis 2012; 89:225-8.

9. Nespoulous L, Matei I, Charissoux A, Bédane C, Assikar S. Symmetrical drug-related intertriginous and flexural exanthema (SDRIFE) associated with pristinamycin, secnidazole, and nefopam, with a review of the literature. Contact Dermatitis 2018; 79:378-80. https://doi.org/10.1111/cod.13084.

10. Weiss D, Kinaciyan T. Symmetrical drug-related intertriginous and flexural exanthema (SDRIFE) induced by mefenamic acid. JAAD Case Rep 2018; 5:89-90. https://doi.org/10.1016/j.jdxcr.20 18.10 .015

11. Karadag AS, Ozlu E, Akdeniz N, Uzuncakmak TK, Turkoglu Z, Ozkanli S, et al. Oral mucosal involvement and petechial lesions: A SDRIFE case with unusual findings. Cutan Ocul Toxicol 2016; 35:157-9. https://doi.org/10.3109/15569527.201 5.1067227.

12. Harbaoui S, Litaiem N. Symmetrical drug-related intertriginous and flexural exanthema (SDRIFE). From: https://www.ncbi. nlm.nih.gov/books/NBK539750/ Accessed: Aug 2019. 